\title{
A Retrospective Study of Patients Undergoing Radical Cystectomy and Receiving Peri-Operative Naloxegol or Alvimopan: Comparison of Length of Stay
}

\author{
Taylor Goodstein ${ }^{1,}$ *, Bryn Launer ${ }^{1}$, Sharon White ${ }^{1}$, Madison Lyon ${ }^{1}$, Nicholas George ${ }^{1}$, \\ Kailynn DeRonde $^{2,3}$, Michelle Burke ${ }^{4}$, Colin O'Donnell ${ }^{1}$, Clark Lyda ${ }^{4}$, Tyree H. Kiser ${ }^{5}$, \\ Shandra Wilson ${ }^{1}$ \\ ${ }^{1}$ Division of Urology, Department of Surgery, University of Colorado Hospital, Aurora, USA \\ ${ }^{2}$ Connecticut Children's Medical Center, Hartford, USA \\ ${ }^{3}$ School of Pharmacy, University of Connecticut, Storrs, USA \\ ${ }^{4}$ Department of Pharmacy, University of Colorado Hospital, Aurora, USA \\ ${ }^{5}$ Department of Clinical Pharmacy, University of Colorado Skaggs School of Pharmacy and Pharmaceutical Sciences, Aurora, USA
}

Email address:

Taylor.a.goodstein@ucdenver.edu (T. Goodstein)

${ }^{*}$ Corresponding author

To cite this article:

Taylor Goodstein, Bryn Launer, Sharon White, Madison Lyon, Nicholas George, Kailynn DeRonde, Michelle Burke, Colin O’Donnell1, Clark Lyda, Tyree H. Kiser, Shandra Wilson. A Retrospective Study of Patients Undergoing Radical Cystectomy and Receiving PeriOperative Naloxegol or Alvimopan: Comparison of Length of Stay. Journal of Surgery. Vol. 6, No. 5, 2018, pp. 129-134.

doi: $10.11648 /$ j.js.20180605.14

Received: August 27, 2018; Accepted: September 10, 2018; Published: October 12, 2018

\begin{abstract}
Alvimopan is a $\mu$-opioid receptor antagonist used in the post-operative period to decrease rates of post-operative ileus (POI) following radical cystectomy (RC) and thereby shorten length of stay (LOS). Naloxegol is a much less expensive drug of the same class that has yet to be studied for prevention of POI in the peri-operative period. The purpose of the current study is to evaluate the differences in LOS and development of POI in patients post-RC who take alvimopan versus those who take naloxegol, with the hope that drug efficacy can be evaluated against the significant difference in cost burden between the two drugs. The study population included all adult patients between 18-89 years of age with bladder cancer undergoing radical cystectomy with urostomy at University of Colorado Hospital. Those patients who received usual post-operative care as well as either alvimopan or naloxegol between September 2011 and December 2017 were selected for analysis. Patients who did not take either medication or were switched from one drug to the other were excluded from the study. A zero-truncated binomial regression analysis was used to analyze differences in length of stay in patients who received alvimopan versus those who received naloxegol. Additionally, the incidence of post-operative ileus was compared between treatment groups. 130 patients who underwent RC and received either alvimopan or naloxegol were included in the study: 75 (58\%) received alvimopan and $55(42 \%)$ received naloxegol. Baseline characteristics were similar between treatment groups. There was no significant difference in the length of stay between patients who received alvimopan and patients who received naloxegol after adjusting for age, sex, BMI, length of surgical time, or stage of disease $(p=0.41)$. There was no significant between the two drugs for development of POI $(p=0.85)$. Development of POI was significantly associated with a longer LOS $(p=0.007)$. The analysis showed that naloxegol was comparable to alvimopan when it came to length of hospital stay following RC. Therefore, naloxegol may be offered as a less expensive, effective alternative to alvimopan.
\end{abstract}

Keywords: Alvimopan, Naloxegol, Post-operative Ileus, Length of Stay, $\mu$-opioid Receptor Antagonist, Radical Cystectomy 


\section{Introduction}

Radical cystectomy ( $\mathrm{RC}$ ) is a complicated abdominopelvic surgical procedure, typically involving the repurposing of small intestine for urinary diversion. [1] One of the main complications following $\mathrm{RC}$ is the development of postoperative ileus (POI), which has been associated with increased length of stay, increased risk of post-operative complications, and an increase in overall cost. [1,2] Various strategies have been implemented to aid gastrointestinal (GI) recovery, including the use of epidural anesthesia, using a less invasive procedure when possible, and the implementation of accelerated post-operative care pathways. [2] However, despite these measures, postoperative ileus still occurs in up to $40 \%$ of patients and adds two to eight additional hospital days and from $\$ 4,000$ to $\$ 9,000$ in cost per patient. [1,2]

Alvimopan is a peripherally acting $\mu$-opioid receptor antagonist FDA approved in 2008 to decrease time to return of GI bowel function. Several phase 3 trials showed that it accelerated GI recovery in patients undergoing laparotomy for bowel resection. [3-8] Since then, evidence has continued to grow establishing that alvimopan reduces rates of POI, length of stay (LOS), and cost burden following $\mathrm{RC}$ and other abdominal surgeries. [1, 9-12] At the time of its approval in 2008 , alvimopan cost $\$ 62.50$ per pill, with a full course costing $\$ 937.50$. A 2010 paper showed that alvimopan saved hospitals \$879-\$977 compared to placebo, suggesting that the use of alvimopan was cost-neutral to cost-saving. [2] Another study has shown that alvimopan saves a total of $\$ 2,640$ per patient. [9]

However, by 2018, the price of alvimopan has increased to $\$ 192.00$ per capsule, with a full 15-dose, 7-day course totaling $\$ 2,880$. A drug of the same class, naloxegol, costs about $\$ 14.05$ per tablet, or $\$ 98.35$ for a comparable course. [13] Naloxegol was approved in 2014 for the treatment of opioid-induced constipation in adult patients with chronic non-cancer pain, but research examining it as a potential short term treatment for opioid-induced constipation has not yielded clear results. [14-17] To the best of our knowledge, naloxegol has not been examined in the post-operative period for the management of POI.

Determining whether naloxegol is comparable to alvimopan in regards to LOS and incidence of POI following $\mathrm{RC}$ could have a significant cost-saving impact in the postoperative course of these patients. The current study aimed to evaluate the LOS and rate of POI in patients treated with naloxegol versus alvimopan.

\section{Methods}

\subsection{Study Design}

The study was approved by the Colorado Multiple Institutional Review Board (COMIRB No: 18-1437). The study was designed as a retrospective review and no interventions were made.

\subsection{Study Population}

The study population included all adult patients between 18-89 years of age with bladder cancer undergoing open radical cystectomy with urostomy by a single surgeon at the University of Colorado Hospital. Patients in the alvimopan group were identified and evaluated between September 2011 to February 2016. The cohort of naloxegol recipients was prospectively identified from those patients who met the requirements of the study population from May 2016 to December 2017, starting at the time when naloxegol became available on the study institution's formulary. All charts were reviewed retrospectively at least 21 days after patient discharge.

Patients were not excluded on the basis of which urinary diversion they received after cystectomy. Patients who did not take either medication or were switched from one drug to the other were excluded from the study. Other exclusion criteria included operation by a different primary surgeon or abortion of cystectomy because of an unresectable tumor, and one incidence of death during the acute post-operative period. Data was collected on patient race, age, sex, ethnicity, smoking status, presence of co-morbid diabetes (DM), cardiovascular disease (CVD) and/or gastroesophageal reflux disease (GERD), BMI, need for blood transfusion during surgery, length of time in surgery, and type of diversion received.

\subsection{Outcome Measures}

The primary outcome measure was length of hospital stay, defined as the number of days from the surgical date until the date that discharge orders were written. The secondary outcome measure was development of post-operative ileus, determined by searching the post-operative urologic progress notes for "ileus" or "POI". The cost of care differences between the two drug cohorts was not analyzed specifically during this study, but information on cost of each drug was obtained from literature review as well as the University of Colorado Hospital's average wholesale price list.

\subsection{Usual Post-Operative Care}

All patients included in this study received usual postoperative care as well as either alvimopan and naloxegol. Usual post-operative care included the following:

(1) Epidural for 4 days: bupivacaine and hydromorphone, rate adjusted for age and side effects.

(2) Transition to oral oxycodone on post-operative day 4, dosed every 6 hours as needed with attempted wean to once before bed before discharge.

(3) NPO status for 1-3 days, until return of bowel function.

(4) Nasogastric (NG) tube for 1-4 days.

(5) Antibiotic prophylaxis for $<24$ hours, usually cefoxitin or cefazolin, although selection was ultimately left to the attending physician.

(6) Monitoring of vital signs, temperature, signs of 
infection, and return of bowel function.

\subsection{Drug Administration}

Both alvimopan and naloxegol were given in the preoperative area 30 to 60 minutes before the start of surgery. Naloxegol was then given once a day at $25 \mathrm{mg}$ or once a day at $12.5 \mathrm{mg}$ in patients with renal dysfunction $(\mathrm{CrCl}<60$ $\mathrm{mL} / \mathrm{min}$ ). Alvimopan was dosed at $12 \mathrm{mg}$ twice a day. Both medications were continued for a maximum of seven days, naloxegol for seven doses (1 dose pre-operatively followed by once daily for six days) or alvimopan for 15 doses (1 dose pre-operatively plus 14 more doses over the next seven days).

\subsection{Statistical Analysis}

Fisher's exact test and Student t-test were used to evaluate categorical and continuous data, respectively. Independent Fisher's exact tests were used to analyze between-group differences in regards to these potential confounding factors. Generalized Estimating Equations logistic regression was used to analyze differences in probability of POI in patients who received alvimopan versus those who received naloxegol. A truncated-zero negative binomial regression was used to determine whether LOS differed between alvimopan and naloxegol. Statistical analysis was performed using SAS (C) 9.4 TS Level 1M3, and R version 3.4.2 (C) The $\mathrm{R}$ Foundation for Statistical Computing. All tests were 2sided. A p-value $<0.05$ was considered significant.

\section{Results}

The study included 130 patients who underwent RC and received either alvimopan or naloxegol (Table 1). Of these, 75 $(58 \%)$ received alvimopan and 55 (42\%) received naloxegol. Ethnicity status was missing for 12 patients, for whom it was not included in the chart. There were no significant differences between the drug cohorts for sex $(p=0.094)$, age (alvimopan mean $66 \pm 5.5$ years, naloxegol mean $64 \pm 5.6$ years; $\mathrm{p}=$ $0.056)$, race $(p=0.52)$, Hispanic ethnicity $(p=0.47)$, BMI (alvimopan mean $26.7 \pm 2.4$, naloxegol mean $27.5 \pm 2.5 ; \mathrm{p}=$ $0.36)$, tumor stage $(\mathrm{p}=0.41)$, smoking status $(\mathrm{p}=0.64)$, or comorbidity $(\mathrm{p}=0.38)$ (Table 1$)$. There was no difference between the drug cohorts for length of time in surgery (alvimopan mean $7 \pm 0.6 \mathrm{hrs}$, naloxegol mean $6.6 \pm 0.7 \mathrm{hrs}$; $\mathrm{p}$ $=0.71$ ). For urinary diversion, 49 patients received ileal conduit, 72 received a neobladder, and 9 received a right colon pouch with catheterizable stoma. There was no significant difference between the two treatment groups in regards to urinary diversion type $(\mathrm{p}=0.98$; Table 2$)$.

Table 1. Demographics and health characteristics of patients who underwent $R C$ and received either alvimopan or naloxegol.

\begin{tabular}{|c|c|c|c|}
\hline & Naloxegol (\%) & Alvimopan (\%) & P value \\
\hline Male & $43(78.2)$ & $59(78.6)$ & \multirow{2}{*}{$0.094^{\beta}$} \\
\hline Female & $12(21.8)$ & $16(21.4)$ & \\
\hline \multicolumn{4}{|l|}{ Race } \\
\hline African American & $1(1.8)$ & $3(4)$ & \multirow{4}{*}{$0.52^{\gamma}$} \\
\hline Caucasian & $42(76.4)$ & $61(81.3)$ & \\
\hline Other & $1(1.8)$ & $11(14.7)$ & \\
\hline Unknown & $11(20)$ & $0(0)$ & \\
\hline \multicolumn{4}{|l|}{ Ethnicity } \\
\hline Non-Hispanic/Latino & $39(70.9)$ & $71(94.7)$ & \multirow{3}{*}{$0.47^{\gamma}$} \\
\hline Hispanic/Latino & $4(7.3)$ & $4(5.3)$ & \\
\hline Unknown & $12(21.8)$ & $0(0)$ & \\
\hline \multicolumn{4}{|l|}{ Age (years) } \\
\hline $18-29$ & $0(0)$ & $1(1.3)$ & \multirow{7}{*}{$0.056^{\beta}$} \\
\hline $30-39$ & $1(1.8)$ & $2(2.7)$ & \\
\hline $40-49$ & $4(7.3)$ & $2(2.7)$ & \\
\hline $50-59$ & $12(21.8)$ & $18(24)$ & \\
\hline $60-69$ & $16(29)$ & $24(32)$ & \\
\hline 70-79 & $18(32.7)$ & $23(30.7)$ & \\
\hline $80+$ & $4(7.3)$ & $5(6.7)$ & \\
\hline \multicolumn{4}{|l|}{ Smoking Status } \\
\hline Smoker & $7(12.7)$ & $11(14.7)$ & \multirow{3}{*}{$0.64^{\beta}$} \\
\hline Non-smoker & $19(34.6)$ & $20(26.6)$ & \\
\hline Former & $29(52.7)$ & $44(58.7)$ & \\
\hline \multicolumn{4}{|l|}{ BMI } \\
\hline$<18.5$ & $1(1.8)$ & $1(1.3)$ & \multirow{4}{*}{$0.36^{\beta}$} \\
\hline $18.5-24.9$ & $15(27.3)$ & $25(33.3)$ & \\
\hline $25-29.9$ & $20(36.4)$ & $36(48)$ & \\
\hline$>30$ & $19(34.5)$ & $13(17.3)$ & \\
\hline \multicolumn{4}{|l|}{ Tumor Stage } \\
\hline. .0 & $5(9.1)$ & $0(0)$ & \multirow{6}{*}{$0.41^{\beta}$} \\
\hline CIS & $3(5.5)$ & $5(6.7)$ & \\
\hline I & $6(10.9)$ & $17(22.7)$ & \\
\hline II & $13(23.6)$ & $31(41.3)$ & \\
\hline III & $15(27.3)$ & $16(21.3)$ & \\
\hline IV & $13(23.6)$ & $6(8)$ & \\
\hline
\end{tabular}




\begin{tabular}{llll}
\hline & Naloxegol (\%) & Alvimopan (\%) & P value \\
\hline Co-morbidities & & & \\
DM & $9(16.4)$ & $14(18.6)$ & $0.378^{\gamma}$ \\
CVD & $8(14.5)$ & $15(20)$ & \\
GERD & $19(34.6)$ & $31(41.3)$ & \\
\hline
\end{tabular}

${ }^{\beta}$ Generalized Estimating Equation; ${ }^{\gamma}$ Independent Fisher Exact Test

Table 2. Urinary diversion used in each treatment group. CUD, continent urinary diversion.

\begin{tabular}{lllll}
\hline & CUD (\%) & Ileal conduit (\%) & Neobladder (\%) & P value \\
\hline Alvimopan & $5(6.7)$ & $42(37.3)$ & $42(56)$ & 0.98 \\
Naloxegol & $4(7.2)$ & $30(38.2)$ & $30(54.5)$ & 0.98 \\
\hline
\end{tabular}

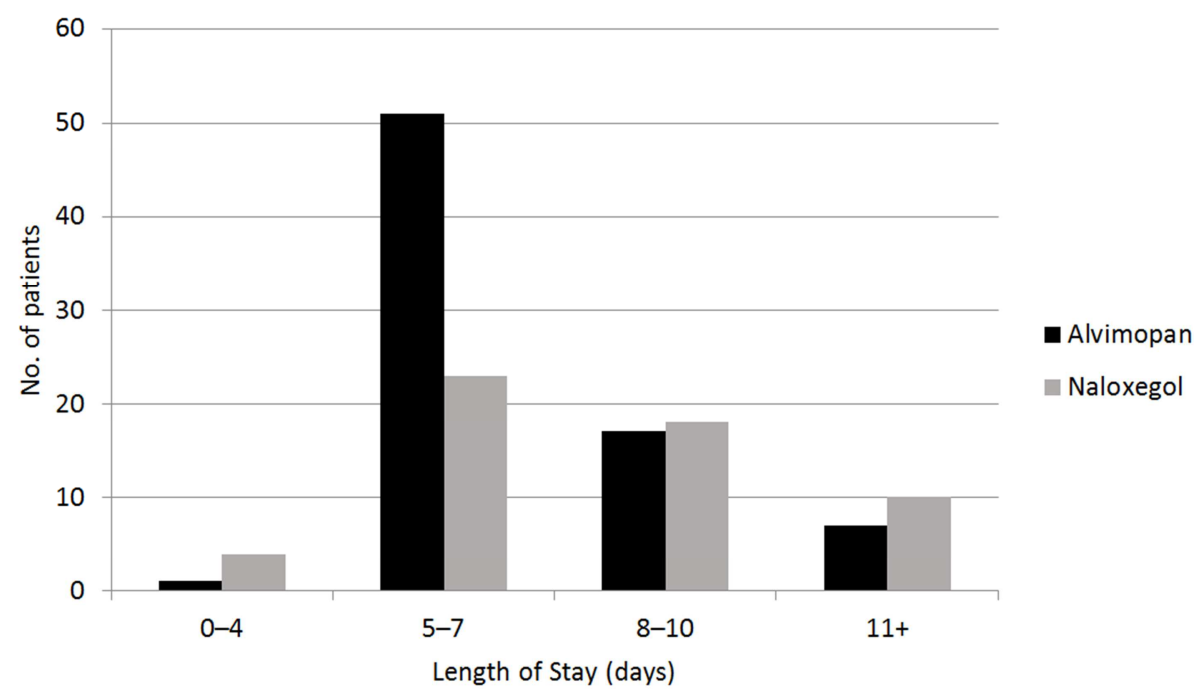

Figure 1. Distribution of length of stay for patients receiving alvimopan or naloxegol.

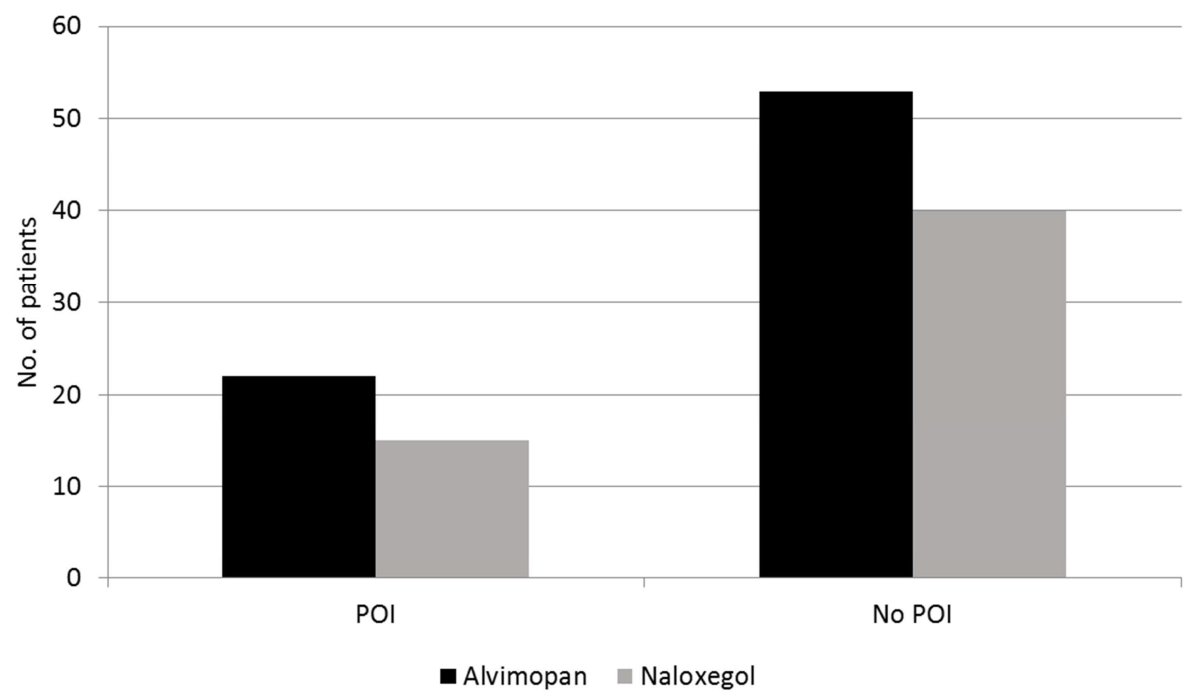

Figure 2. Incidence of POI for patients receiving alvimopan or naloxegol.

Mean LOS was $7.6( \pm 1.85)$ days for alvimopan and $8.6( \pm$ 2.1) days for naloxegol, which, after adjusting for age, stage of disease, sex, BMI, and length of time in surgery, was not significant $(\mathrm{p}=0.41$; Figure 1). POI occurred in $22(29 \%)$ alvimopan-treated patients compared to $15(27 \%)$ naloxegoltreated patients, which was not a significant difference $(\mathrm{p}=$ 0.85; Figure 2). Incidence of POI was associated with a significant increase in $\operatorname{LOS}(\mathrm{p}=0.007)$. Presence of any of the measured co-morbidities (DM, CVD, GERD) was also associated with a significant increase in $\operatorname{LOS}(p=0.48)$. We did not detect a significant relationship between LOS and need for blood transfusion during surgery $(p=0.22)$ or smoking status $(\mathrm{p}=0.09)$. 


\section{Discussion}

The LOS of alvimopan recipients in this study was comparable to other similar studies. [1, 12, 18-20] This study did not find a significant difference between naloxegol and alvimopan in regards to LOS, which suggests that naloxegol is non-inferior to alvimopan when it comes to facilitating GI recovery following RC. There was also no significant difference between naloxegol and alvimopan in regards to incidence of POI.

This represents an off-label use for naloxegol, which has been approved for managing opioid-induced constipation in adult patients with chronic non-cancer pain and to the best of our knowledge has not been examined in the post-operative period. Alvimopan is only used during the post-operative period, as it has not been approved for courses longer than 15 doses due to a higher incidence of myocardial infarct (MI) in patients on alvimopan long term. [8]

LOS is an appropriate surrogate marker for POI, as this has been demonstrated in other studies, and indeed, in this study it was found that incidence of POI was itself associated with a longer $\operatorname{LOS}(p=0.007)$. [1,2] Also associated with a longer LOS was the presence of any of the measured comorbidities, which suggests that LOS is influenced by overall health of the patient.

The most common urinary diversion used after cystectomy is ileal conduit, at an estimated 92\%. [21] However, within tertiary care centers like the study institution, type of urinary diversion used after cystectomy varies widely. One tertiary care center examined patients over 60 years of age who received urinary diversion and found that $41 \%$ received a neobladder, 33\% receiving a non-orthotopic continent diversion, and only $25 \%$ received an ileal conduit. [22] In addition, a study of 570 patients treated at European tertiary care centers showed that $29 \%$ of patients received a neobladder, $3 \%$ received a pouch, and 59\% received an ileal conduit. [23] Comparatively, the population used in the present study saw a much higher rate of neobladder construction following cystectomy (56\% and $54.5 \%$ for alvimopan and naloxegol cohorts, respectively).

Limitations of this study include its retrospective design, which cannot eliminate the possibility for bias. For this reason, data was gathered to assess different factors that could independently influence the measured outcomes. The gathered data demonstrates that the two groups were comparable for every analyzed variable. However, data was not gathered on differences in opioid use (whether pre-, intraor post- procedure) between the two groups, which represents a potential confounding factor. Furthermore, drug recipients were gathered during different time periods (alvimopan from 2011-2016 and naloxegol from 2016-2017), and though all patients were operated on by the same surgeon and received the same post-operative protocol, other possible changes over time, such as anesthesia technique or nursing protocols, cannot be eliminated.

One important consideration for use of naloxegol in the post-operative period is its higher reported incidence of dyspepsia (21\% vs. $1.5 \%$ in alvimopan). $[8,14]$ In this study, no patients had to stop taking naloxegol because of this side effect, but data was not collected on the use of anti-emetics or incidence of post-operative nausea/vomiting to determine other clinical implications and potential cost effects of dyspepsia in patients on naloxegol vs. alvimopan.

Alvimopan is currently the only $\mu$-opioid receptor antagonist approved for facilitating GI recovery in the postoperative period. It cannot be used long-term because of a higher incidence of MI noted during clinical trials. [8] Though it has been shown to save costs by reducing LOS, it has grown to become a significantly more expensive drug. Naloxegol is much less expensive and, by this study, appears to be as effective as alvimopan for facilitating post-operative GI recovery.

\section{Conclusion}

Naloxegol administration in the peri-operative period has yet to be studied for the prevention of POI and reduction of LOS. This study, examining patients undergoing radical cystectomy for bladder cancer, suggests that naloxegol provides a similar LOS and incidence of POI compared to the traditionally used alvimopan. This could represent an opportunity for considerable cost savings within perioperative care, and further study looking at naloxegol administration for other operations and patient groups is warranted.

\section{Funding}

This study was supported by the Colorado Clinical and Translational Sciences Institute (CCTSI). The CCTSI is supported in part by Colorado CTSA Grant UL1TR001082 from NCATS/NIH.

\section{References}

[1] Lee, C. T. et al. Alvimopan Accelerates Gastrointestinal Recovery After Radical Cystectomy: A Multicenter Randomized Placebo-Controlled Trial. Eur. Urol. 66, 265-272 (2014).

[2] Kraft, M., MacLaren, R., Du, W. \& Owens, G. Alvimopan (Entereg) for the Management Of Postoperative Ileus in Patients Undergoing Bowel Resection. Pharm. Ther. 35, 4449 (2010).

[3] Delaney, C. P. et al. Phase III trial of alvimopan, a novel, peripherally acting, mu opioid antagonist, for postoperative ileus after major abdominal surgery. Dis. Colon Rectum 48, 1114-1125; discussion 1125-1126; author reply 1127-1129 (2005).

[4] Viscusi, E. R. et al. Alvimopan, a peripherally acting muopioid receptor antagonist, compared with placebo in postoperative ileus after major abdominal surgery: results of a randomized, double-blind, controlled study. Surg. Endosc. 20, 64-70 (2006). 
[5] Wolff, B. G. et al. Alvimopan, a novel, peripherally acting mu opioid antagonist: results of a multicenter, randomized, double-blind, placebo-controlled, phase III trial of major abdominal surgery and postoperative ileus. Ann. Surg. 240, 728-734; discussion 734-735 (2004).

[6] Ludwig, K. et al. Gastrointestinal tract recovery in patients undergoing bowel resection: results of a randomized trial of alvimopan and placebo with a standardized accelerated postoperative care pathway. Arch. Surg. Chic. Ill 1960 143, 1098-1105 (2008)

[7] Büchler, M. W. et al. Clinical trial: alvimopan for the management of post-operative ileus after abdominal surgery: results of an international randomized, double-blind, multicentre, placebo-controlled clinical study. Aliment. Pharmacol. Ther. 28, 312-325 (2008).

[8] ENTEREG ${ }^{\circledR}$ (alvimopan) | Official Site. Available at: https://www.merckconnect.com/entereg/overview.html. (Accessed: 5th April 2018)

[9] Kauf, T. L. et al. Alvimopan, a Peripherally Acting $\mu$-Opioid Receptor Antagonist, is Associated with Reduced Costs after Radical Cystectomy: Economic Analysis of a Phase 4 Randomized, Controlled Trial. J. Urol. 191, 1721-1727 (2014).

[10] Cui, Y., Chen, H., Qi, L., Zu, X. \& Li, Y. Effect of alvimopan on accelerates gastrointestinal recovery after radical cystectomy: A systematic review and meta-analysis. Int. J. Surg. Lond. Engl. 25, 1-6 (2016).

[11] Earnshaw, S. R. et al. Economic Impact of Alvimopan Considering Varying Definitions of Postoperative Ileus. J. Am. Coll. Surg. 221, 941-950 (2015).

[12] Sultan, S., Coles, B. \& Dahm, P. Alvimopan for recovery of bowel function after radical cystectomy. Cochrane Database Syst. Rev. 5, CD012111 (2017).

[13] K Dodson, PharmD \& Clark Lyda, Pharm D. Average Wholesale Price (AWP) of Alvimopan and Naloxegol. (2018).

[14] MOVANTIK $®$ (naloxegol)|Opioid Induced Constipation Treatment. Available at: https://www.movantik.com/home.html. (Accessed: 5th April 2018)
[15] Nee, J. et al. Efficacy of Treatments for Opioid-induced Constipation: A Systematic Review and Meta-Analysis. Clin. Gastroenterol. Hepatol. Off. Clin. Pract. J. Am. Gastroenterol. Assoc. (2018). doi:10.1016/j.cgh.2018.01.021

[16] Halawi, H. et al. Effects of naloxegol on whole gut transit in opioid-naïve healthy subjects receiving codeine: A randomized, controlled trial. Neurogastroenterol. Motil. Off. J. Eur. Gastrointest. Motil. Soc. (2018). doi:10.1111/nmo.13298

[17] Grønlund, D. et al. The impact of naloxegol on anal sphincter function - Using a human experimental model of opioidinduced bowel dysfunction. Eur. J. Pharm. Sci. Off. J. Eur. Fed. Pharm. Sci. 117, 187-192 (2018).

[18] Manger, J. P. et al. Alvimopan: A cost-effective tool to decrease cystectomy length of stay. Cent. Eur. J. Urol. 67, 335-341 (2014).

[19] Tobis, S. et al. Effect of alvimopan on return of bowel function after robot-assisted radical cystectomy. J. Laparoendosc. Adv. Surg. Tech. A 24, 693-697 (2014).

[20] Vora, A. A. et al. Alvimopan provides rapid gastrointestinal recovery without nasogastric tube decompression after radical cystectomy and urinary diversion. Can. J. Urol. 19, 62936298 (2012).

[21] Kim, S. P. et al. Population-based trends in urinary diversion among patients undergoing radical cystectomy for bladder cancer. BJU Int. 112, 478-484 (2013).

[22] Clark, P. E. et al. Radical cystectomy in the elderly: comparison of clincal outcomes between younger and older patients. Cancer 104, 36-43 (2005).

[23] Schmid, M. et al. Evidence from the 'PROspective MulticEnTer RadIcal Cystectomy Series 2011 (PROMETRICS 2011)' study: how are preoperative patient characteristics associated with urinary diversion type after radical cystectomy for bladder cancer? Ann. Surg. Oncol. 22, 1032-1042 (2015). 